\title{
Introducing an Optimal Liver Allocation System for Liver Cirrhosis Patients
}

\author{
Jamileh Abolghasemi ${ }^{1}$, Mohammad Reza Eshraghian ${ }^{1, *}$, Mohsen Nasiri Toosi ${ }^{2}$, Mahmood \\ Mahmoodi ${ }^{1}$, Abbas Rahimi Foroushani ${ }^{1}$ \\ ${ }^{1}$ Department of Epidemiology and Biostatistics, School of Public Health, Tehran University of Medical Sciences, Tehran, IR Iran \\ 2 Department of Gastroenterology, School of Medicine, Tehran University of Medical Sciences, Tehran, IR Iran \\ *Corresponding author:Mohammad Reza Eshraghian, Department of Epidemiology and Biostatistics, School of Public Health, Tehran University of Medical Sciences, Tehran, IR Iran. \\ Tel:+98-2188989127, Fax:+98-2188989127, E-mail: eshraghianm@tums.ac.ir.
}

Received: January 29, 2013; Revised: February 08, 2013; Accepted: February 20, 2013

\begin{abstract}
Background: Liver transplantation (LT) is the only treatment option for patients with advanced liver disease. Currently, liver donation to these patients, considering priorities, is based on the Model for End-Stage Liver Disease(MELD). MELD score is a tool for predicting the risk of mortality in patients with advanced liver disease. However, few studies have so far been conducted in Iran on the efficacy of MELD score of these patients.

Objectives: This study reviews the present status of the MELD score and introduces a new model for optimal prediction of the risk of mortality in Iranian patients with advanced liver disease.

Patients and Methods: Data required were collected from 305 patients with advanced liver disease who enrolled in a waiting list(WL) in Imam Khomeini Hospital from May 2008 to May 2009. All of the patients were followed up for at least 3 years until they died or underwent LT. Cox regression analysis was applied to select the factors affecting their mortality. Survival curves were plotted. Wilcoxson test and receiver operating characteristics curves for survival predictive model were used to compare the scores. All calculations were performed with the SPSS (version 13.0) and R softwares.

Results: During the study, 71 (23.3\%) patients died due to liver cirrhosis and 43 (14.1\%) underwent LT. Viral Hepatitis (43.7\%) is the most common cause of end-stage liver disease among Iranian patients. A new model (NMELD) was proposed with the use of the natural logarithms of two blood serum variables (total bilirubin and albumin) and the patients' age (year) by applying the Cox model:

NMELD $=10 \times(0.736 \times \ln ($ bilirubin $)-1.312 \times \ln ($ albumin $)+0.025 \times$ age +1.776$)$

Conclusions: The results of the Wilcoxon test showed that there is a significant difference between the usual MELD and our proposed NMELD scores $(\mathrm{P}<0.001)$. Receiver operating characteristics curve for survival predictive model indicated that the NMELD score is more efficient compared with the MELD score in predicting the risk of mortality. Since serum creatinine was not significant in NMELD score, further studies to clarify this issue are suggested.
\end{abstract}

Keywords: Liver Transplantation; End-Stage Liver Disease; Allocation; Liver Cirrhosis

\section{Background}

Gastrointestinal and liver diseases are among the most common causes of morbidity in Iran and constitute a substantial proportion of mortality, which imposes enormous economic consequences $(1,2)$. Prognosis is an important part of the baseline assessment of any disease. It is not only the basis of the information that a physician provides to the patient, but is also the basis for any management method. Proper prioritization of patients waiting in queue for a liver transplant (LT) is needed and many methods have been developed for this purpose over several decades (3). In 1964, Child and Turcotte proposed a prognostic model for estimation of surgical risks in patients with advanced liver disease. Pugh et al. proposed a revision of this model in 1973. The modified
Child-Pugh (CP) prognostic index has been widely used for risk stratifying of patients with cirrhosis and to assess the efficacy of beneficial procedures. At present, the $\mathrm{CP}$ classification is by far the most extensively applied system, as it is easy to use at the bedside (4-8). In 2000, the Department of Health and Human Services (DHHS) of the USA adopted the 'Final Rule'. According to this rule, the primary guidelines for allocation of cadaver livers for transplantation should be based on medical urgency. Over the years, liver allocation policy has evolved from prioritizing liver transplant candidates based on their physical location (home, hospital or intensive care unit) to medical-based criteria (CP score) consistent with these guidelines $(5,9)$. The scoring system of the model for endstage liver disease (MELD) has emerged as an excellent

Implication for health policy/practice/research/medical education:

Liver Transplantation is the only treatment option for patients with advanced liver disease. However, there are a few studies on the efficacy of MELD score among Iranian patients. If prioritization of liver donation is truly optimized, the mortality rate of patients with advanced liver disease will be considerably decreased.

Copyright (C) 2013, KowsarCorp.; Licensee Kowsar Ltd. This is an Open Access article distributed under the terms of the Creative Commons Attribution License (http:/ creativecommons.org/licenses/by/3.0), which permits unrestricted use, distribution, and reproduction in any medium, provided the original work is properly cited. 
predictor of mortality on the waiting list (WL) (10-13). The combination of WL mortality risk and post-transplant mortality risk assessed by the MELD score and other factors can be used to estimate whether candidates are likely to derive a survival benefit from a LT. Recently, MELD score has replaced CP score in the USA for prioritizing donor liver allocation (14-27). The introduction of the MELD system for transplant allocation in the USA resulted in a $3.5 \%$ reduction in WL mortality while early survival of LT recipients remained unchanged despite the selection of more ill patients for transplantation (28). In 1991, the first LT was carried out in Iran. Currently, more than 100 LT are being carried out annually in several provinces including Tehran and Shiraz. At present, MELD and CP scores are widely used to stratify patients for LT in Iran (29-32).

\section{Objectives}

LT is recognized as the only way to treat patients with cirrhosis. The aim of this study was to determine the best time for LT and the factors influencing these patients mortality. Optimal allocation of the few available donor livers for WL is essential. In this study, the survival rate of patients awaiting LT for one, two and three years, and the related influential factors were examined. Here, we attempt to provide a more efficient scoring system than the previous for predicting the mortality risk of patients with advanced liver disease.

\section{Patients and Methods}

We evaluated all of the patients with advanced liver disease on the WL for LT in Imam Khomeini Hospital(Tehran, Iran) during May 2008 to May 2009. They were followed up for 3 years. The required data included demographic features, cause of cirrhosis and laboratory test results. Child-Pugh (CP) score was evaluated by five parameters: ascites, encephalopathy, bilirubin, prothomobin time and albumin. CP scores of all participants were calculated according to the method summarized in Table 1. CP scores ranged from 5 to 15 and allowed the categorization of the patients into 3 groups (23): a) $\mathrm{CP}<7$, b) $6<\mathrm{CP}<9$ and c) $\mathrm{CP}>8$.

\begin{tabular}{llll}
\hline Table 1. Child-Pugh Scores' Calculating Method \\
\hline Criteria & \multicolumn{4}{c}{ CP risk class points } \\
\cline { 2 - 4 } & $\begin{array}{l}\text { A (1 } \\
\text { point) }\end{array}$ & $\begin{array}{l}\text { B (2 } \\
\text { points })\end{array}$ & $\begin{array}{l}\text { C (3 } \\
\text { points })\end{array}$ \\
\hline Ascites & None & Light & Large \\
\hline Serum bilirubin, $\mathbf{m g} / \mathbf{d L}$ & $<30$ & $30-50$ & $>50$ \\
\hline Serum albumin, g/dL & $>35$ & $28-35$ & $<28$ \\
Prothrombin index & $>54$ & $44-54$ & $<44$ \\
\hline Encephalopathy & None & Minimal & Advanced \\
Total score & $5-6$ & $7-9$ & $10-15$ \\
\hline
\end{tabular}

MELD calculations were done on the natural logarithms (ln) of three variables in blood serum: total bilirubin, creatinine and the international normalized ratio (INR) of prothrombin. MELD score was calculated by the following formula:

MELD $=9.6 \times \ln ($ creatinin $\mathrm{mg} / \mathrm{dL})+11.2 \times \ln ($ INR $)+3.8 \times$ $\ln$ (bilirubin $\mathrm{mg} / \mathrm{dL})+6.43$

According to the United Network for Organ Sharing (UNOS) modifications, the laboratory values below 1.0 were rounded to 1 to avoid negative scores, and the maximum serum creatinine considered within the MELD equation was $4.0 \mathrm{mg} / \mathrm{dL}$. In this paper, CP and MELD scores were calculated at the beginning of the study for all patients. Censorship group included the patients that underwent LT during this period or did not die by the end of the study. The univariate Cox regression models were applied separately to discriminate each significant factor. The adjusted survival and hazard functions were estimated using a multivariate Cox regression model. Factors associated with P-values of less than 0.20 for the previous stage (univariate Cox models) were candidates for multivariate analysis. In all models, factors with $\mathrm{P}$ Values $<0.05$ were considered to be significant (33). The resulting predictive formula was normalized to the same scale as the MELD score by linear regression (34). To compare the new scores with the MELD scores, we used ROC curves for survival predictive accuracy. For a binary disease outcome, receiver operating characteristics curve (ROC) is a popular method for displaying sensitivity and specificity of a continuous diagnostic marker. However, some disease outcomes are time dependent, and ROC curves that vary as a function of time may be more appropriate. Standard Cox proportional hazard output can be used to obtain estimates of time dependent sensitivity and specificity, and time dependent ROC curves (35-37). In our study, these special Roc curves were used for predictive accuracy of survival models. About one-third of the patients (101), termed group 1, were randomly selected for score validation and the remaining patients (204) were named as Group 2. Group 2 was used for modeling of NMELD scores, and Group 1 was used for its validation.

\section{Results}

Of the 305 patients, 126 (41.3\%) were females and 179 (58.7\%) were males. The mean age of the patients was 40.67 ( \pm 14.39) (Mean \pm (Standard Deviation) $(\mathrm{M} \pm \mathrm{SD})$ years. The age range was between 18 and 71 years. During the study, 71 (23.3\%) patients died due to complications of liver cirrhosis and 43 (14.1\%) underwent LT. Survival rate at one, two and three years after enrolling in the WL was $82 \%, 73 \%$ and $66 \%$, respectively. Survival rate at one, two and three years for patients with MELD scores $<10$ was $95 \%, 90 \%$ and $79 \%$, for $9<$ MELD $<20$ was $89 \%, 79 \%$ and $75 \%$, and for MELD > 19 was 55\%, $40 \%$ and 27\%, respectively. 
Figure 1 indicates that the mortality rate of patients with high MELD and CP scores was higher than those with lower MELD and CP scores. Using CP scores, $23.9 \%$ of patients were at stage A, $47.9 \%$ at stage B and $28.2 \%$ at stage $C$. Wilcoxon test showed no significant difference between MELD and CP scores $(\mathrm{P}=0.112)$. In this study, the most frequent etiology of cirrhosis was hepatitis, and the rate of liver failure associated with viral hepatitis, autoimmune and cryptogenic was $34.7 \%, 16.4 \%$ and $22.6 \%$, respectively. The detailed data of demographic variables are given in Table 2 .

\section{Figure 1. Kaplan-Meier Survival Curves for CP and MELD Scores}
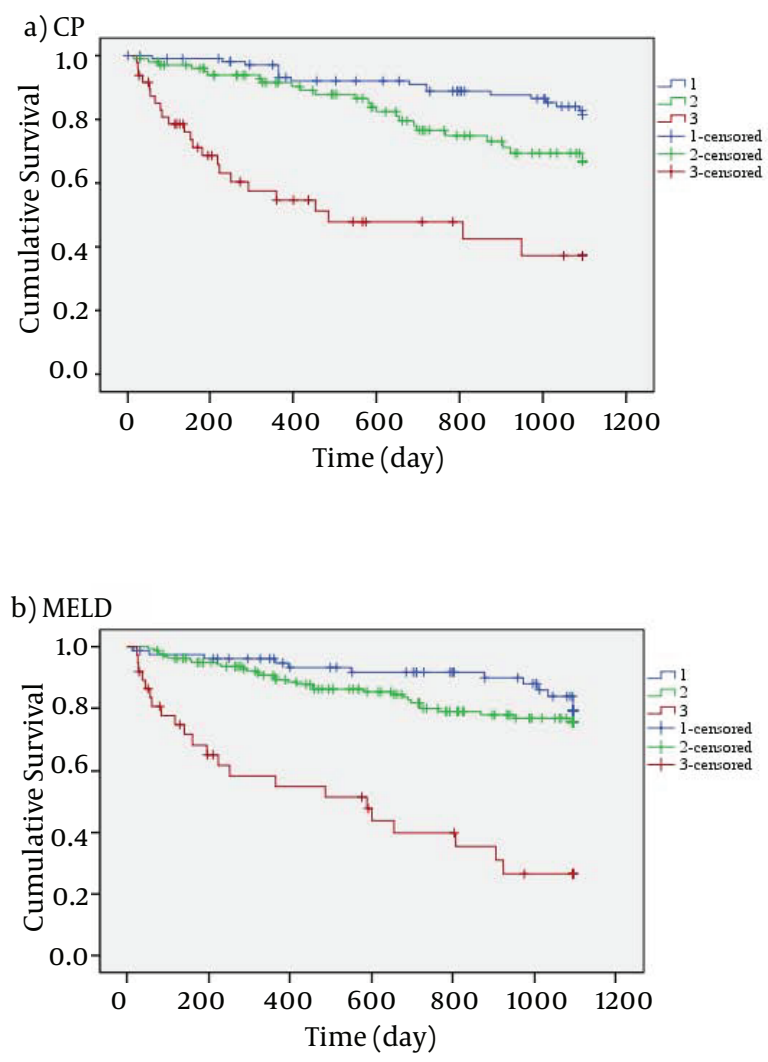

a) Categories of CP scores:1) $\mathrm{CP}<6$ as class A, 2) $\mathrm{CP}$ 7-9 as class $\mathrm{B}$ and 3) $\mathrm{CP}>$ 10 as class $\mathrm{C}$ b) Categories of MELD score: 1) MELD < 10, 2) MELD 10-19 and 3) MELD $>20$

Table 2. Demographic, Clinical, Biochemical Features of Patients Awaiting Liver Transplantation

\begin{tabular}{|clcc}
\hline Demographic & Total & Group 1 & Group 2 \\
\hline Gender, No. (\%) & & & \\
Male & $180(58.7)$ & $59(58.4)$ & $121(59.3)$ \\
Female & $125(41.3)$ & $42(41.6)$ & $83(40.7)$ \\
Education, No. (\%) & & & \\
Primary & $94(30.8)$ & $36(35.7)$ & $58(28.4)$
\end{tabular}

$\begin{array}{llll}\text { Secondary } & 168(55.1) & 52(51.5) & 116(56.9) \\ \begin{array}{l}\text { High educa- } \\ \text { tion }\end{array} & 43(14.1) & 13(12.8) & 30(14.7)\end{array}$

Marriage status,

No. (\%)

$\begin{array}{llll}\text { Single } & 83(27.2) & 24(23.8) & 59(28.9) \\ \text { Married } & 216(70.8) & 75(74.2) & 141(69.1) \\ \begin{array}{l}\text { Divorced or } \\ \text { widow }\end{array} & 6(2.0) & 2(2.0) & 4(2.0)\end{array}$

Family history of

the liver disease,

No. (\%)

$\begin{array}{llll}\text { Yes } & 36(11.8) & 17(16.8) & 19(9.3) \\ \text { No } & 269(88.2) & 84(83.2) & 185(90.7)\end{array}$

Cause of cirrhosis,

No. (\%)

\begin{tabular}{llll}
$\begin{array}{l}\text { Hepatitis B } \\
\text { virus }\end{array}$ & $66(21.6)$ & $27(26.7)$ & $39(19.1)$ \\
$\begin{array}{l}\text { Hepatitis C } \\
\text { virus }\end{array}$ & $40(13.1)$ & $14(13.9)$ & $26(12.7)$ \\
Auto Immune & $50(16.4)$ & $19(18.8)$ & $31(15.2)$ \\
\hline $\begin{array}{l}\text { Cryptogenic } \\
\text { Alcohol }\end{array}$ & $69(22.6)$ & $17(16.8)$ & $52(25.5)$ \\
\hline PSC & $27(0.7)$ & $1(1.0)$ & $1(0.5)$ \\
\hline PBC & $12(3.9)$ & $5(5.0)$ & $22(10.8)$ \\
Others & $39(12.8)$ & $15(14.8)$ & $24(11.8)$
\end{tabular}

Clinical Ascites,

No. (\%)

$\begin{array}{llll}\text { None } & 201 & 69(68.3) & 132(64.7) \\ \text { Light } & 93 & 26(25.8) & 67(32.8) \\ \text { Large } & 11 & 6(5.9) & 5(2.5)\end{array}$

Encephalopathy,

No. (\%)

$\begin{array}{llll}\text { None } & 137(44.9) & 58(57.4) & 81(39.7) \\ \text { Minimal } & 96(31.5) & 38(37.6) & 58(28.4) \\ \text { Advanced } & 72(23.6) & 5(5.0) & 65(31.9)\end{array}$

Biochemical,

mean \pm SD

\begin{tabular}{|c|c|c|c|}
\hline $\begin{array}{l}\text { Serum biliru- } \\
\text { bin }\end{array}$ & $4.290 \pm 6.394$ & $\begin{array}{l}4.200 \pm \\
.480\end{array}$ & $4.466 \pm .587$ \\
\hline $\begin{array}{l}\text { Serum creati- } \\
\text { nine }\end{array}$ & $0.990 \pm 1.177$ & $\begin{array}{l}1.024 \pm \\
.101\end{array}$ & $0.924 \pm .056$ \\
\hline $\begin{array}{l}\text { Serum albu- } \\
\text { min }\end{array}$ & $3.686 \pm 2.285$ & $\begin{array}{l}3.617 \pm \\
.123\end{array}$ & $3.821 \pm .318$ \\
\hline $\begin{array}{l}\text { for prothrom- } \\
\text { time }\end{array}$ & $1.695 \pm .744$ & $\begin{array}{l}1.661 \pm \\
.054\end{array}$ & $1.761 \pm .074$ \\
\hline
\end{tabular}

In Group 2, 83 (40.7\%) were females and 121 (59.3\%) were males. $48(23.5 \%)$ patients in this group died due to complications of liver cirrhosis and 27 (13.2\%) underwent LT. The mean age of the patients was $41.6( \pm 0.98)$ (Mean \pm (Standard Error) $(\mathrm{M} \pm(\mathrm{SE})$ ) years. The age range was be- 
tween 18 and 65 years. In univariate analysis, continuous variables showed a significant association with the patients' age $(\mathrm{P}=0.009)$, $\ln$ (bilirubin) $(\mathrm{P}<0.001)$, In (albumin $)(P<0.001)$ and $\ln ($ INR $)(P<0.001)$. Categorical variables revealed an association between ascites $(\mathrm{P}<0.045)$ and encephapolathy $(\mathrm{P}=0.013)$. The results of univariate analysis are shown in Table 3.

Table 3. Univariate Analysis of Risk Factors Associated With Mortality in Cirrhotic Patients

\begin{tabular}{llll}
\hline Variables & $\begin{array}{l}\text { Regression } \\
\text { coefficient }\end{array}$ & $\begin{array}{l}\text { Regression } \\
\text { coefficient } \\
\text { standard } \\
\text { error }\end{array}$ & $\begin{array}{l}\mathbf{P} \\
\text { value }\end{array}$ \\
\hline Ascites (+) & 0.496 & 0.242 & 0.045 \\
$\begin{array}{l}\text { Encephalopa- } \\
\text { thy (+) }\end{array}$ & 1.445 & 0.582 & 0.013 \\
Age & 0.014 & 0.006 & 0.009 \\
ln(bilirubin) & 0.818 & 0.131 & $<0.001$ \\
\hline $\ln$ (albomin) & -1.836 & 0.469 & $<0.001$ \\
\hline $\ln$ (INR) & 1.555 & 0.341 & $<0.001$ \\
\hline
\end{tabular}

Cox multiple regression analysis indicated that there is a statistically significant correlation between In (bilirubin), ln (albumin) and age, and the risk of mortality. The results of multivariate analysis are shown in Table 4.

Table 4. Multivariate Analysis of Risk Factors Associated With Mortality in Cirrhotic Patients

\begin{tabular}{llll}
\hline Variables & $\begin{array}{l}\text { Regres- } \\
\text { sion coef- } \\
\text { ficient }\end{array}$ & $\begin{array}{l}\text { Regression } \\
\text { coefficient stan- } \\
\text { dard error }\end{array}$ & P- value \\
\hline In(bilirubin) & 0.979 & 0.153 & $<0.001$ \\
ln(albomin) & -1.745 & 0.469 & $<0.001$ \\
Age & 0.033 & 0.011 & 0.010 \\
\hline
\end{tabular}

The score of the optimal model was calculated via the below formula:

$\mathrm{A}=0.979 \times \ln ($ bilirubin $)-1.745 \times \ln ($ albumin $)+0.033$ $\times$ age

By linear regression, we found that the best linear fit between A (as independent variable) and the MELD score (as dependent variable) was provided by a line with the slope of 7.519 and an intercept of 17.661 . The correlation between the two was good with $\mathrm{R}=0.560$. Based on the above analysis, the scores obtained from the model can be derived from the below formula. Here, we've termed it the 'New MELD (NMELD)' score:

NMELD $=10 \times(0.736 \times \ln ($ bilirubin $)-1.312 \times \ln ($ albumin $)$ $+0.025 \times$ age +1.776$)$

To avoid negative scores, serum bilirubin values below 1.0 were rounded to 1 and serum albumin values over 5.4 were rounded to 5.4; the obtained scores were rounded to the nearest integer. All analyses for modeling of NMELD

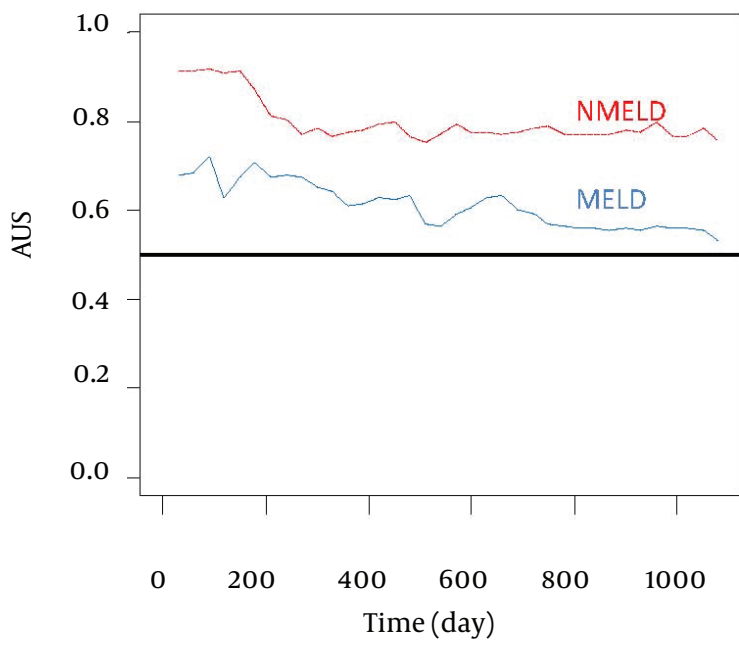

Figure 2. Accuracy of the NMELD Score (Dash Line) Using the Covariates of $\ln$ (Bilirubin), $\ln$ (Albumin) and age vs. MELD (Solid Line) Score Using the Covariates of $\ln$ (Bilirubin), $\ln$ (INR) and $\ln$ (Creatinine). Lines Plot the Estimates of Incident/Dynamic AUC ( $t$ ) Versus Time Under the Assumption of Proportional Hazards.

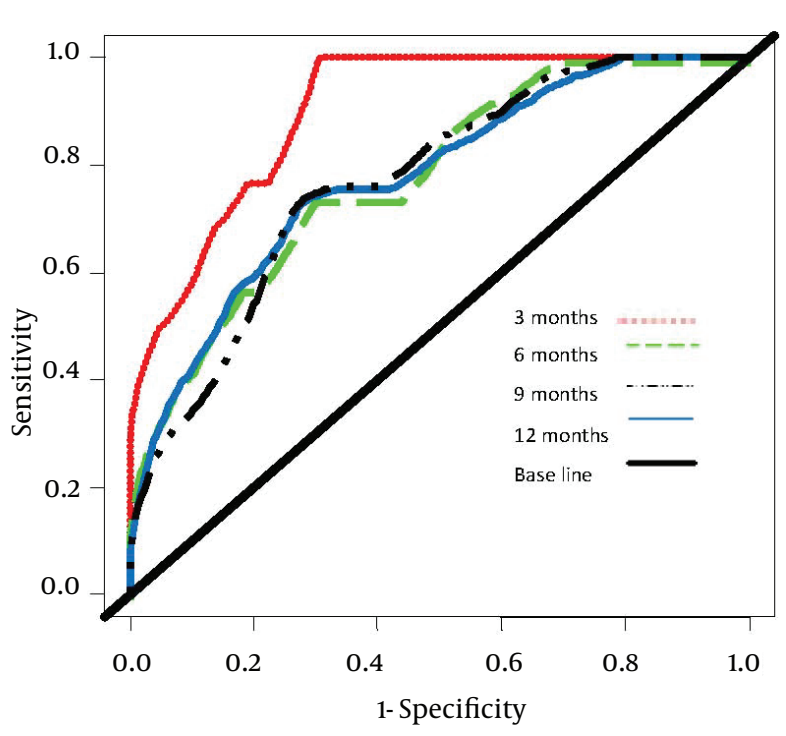

Figure 3. Comparison of the Area Under ROC Curves (AUC) for Predicting the Risk of Mortality at 3 (AUC $=0.916), 6(\mathrm{AUC}=0.811$ ), 9 (AUC $=0.788)$ and $12($ AUC $=0.780)$ Months for NMELD Scores.

were done based on the data collected from Group 2. In Group 1, 42 (41.6\%) individuals were females and 59 (58.4\%) were males. $23(22.8 \%)$ patients in this group died due to complications of liver cirrhosis and 16 (15.8\%) underwent LT. The mean age of the patients was $40.2( \pm 1.53)$ years. The age range was between 18 and 71 years.

Comparison of accuracy of the NMELD Score (Dash Line) 
Using the Covariates of $\ln$ (Bilirubin), ln (Albumin) and age vs. MELD Score (Solid Line) Using the Covariates of ln (Bilirubin), ln (INR) and ln (Creatinine). Lines Plot the Estimates of Incident/Dynamic AUC ( $\mathrm{t}$ ) Versus Time Under the Assumption of Proportional Hazards. Figure 2 shows that the NMELD score is superior in predicting the risk of mortality. Since the AUC values for MELD score are about 0.5 , this model is inefficient for predicting the risk of mortality. Figure 3 shows that NMELD score is more accurate than MELD score in assessing the risk of mortality in the short term. Comparisons of the NMELD and MELD scores were performed based on data collected from Group 1.

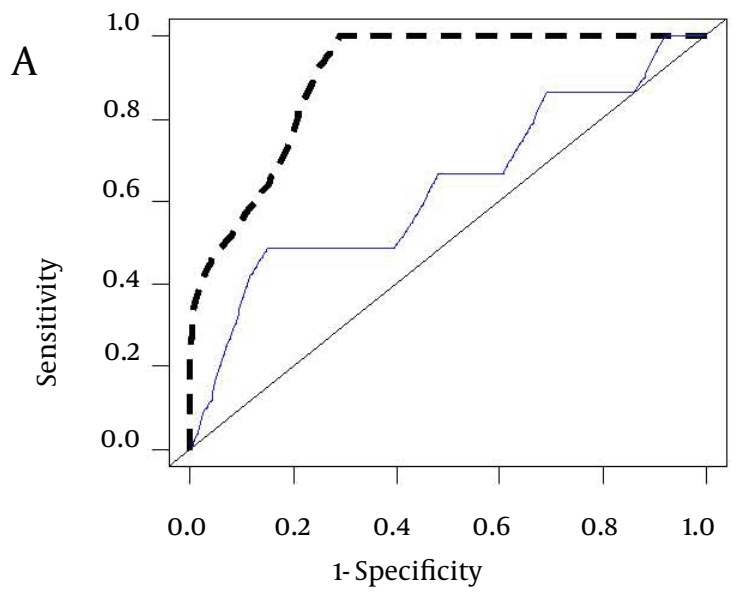

B
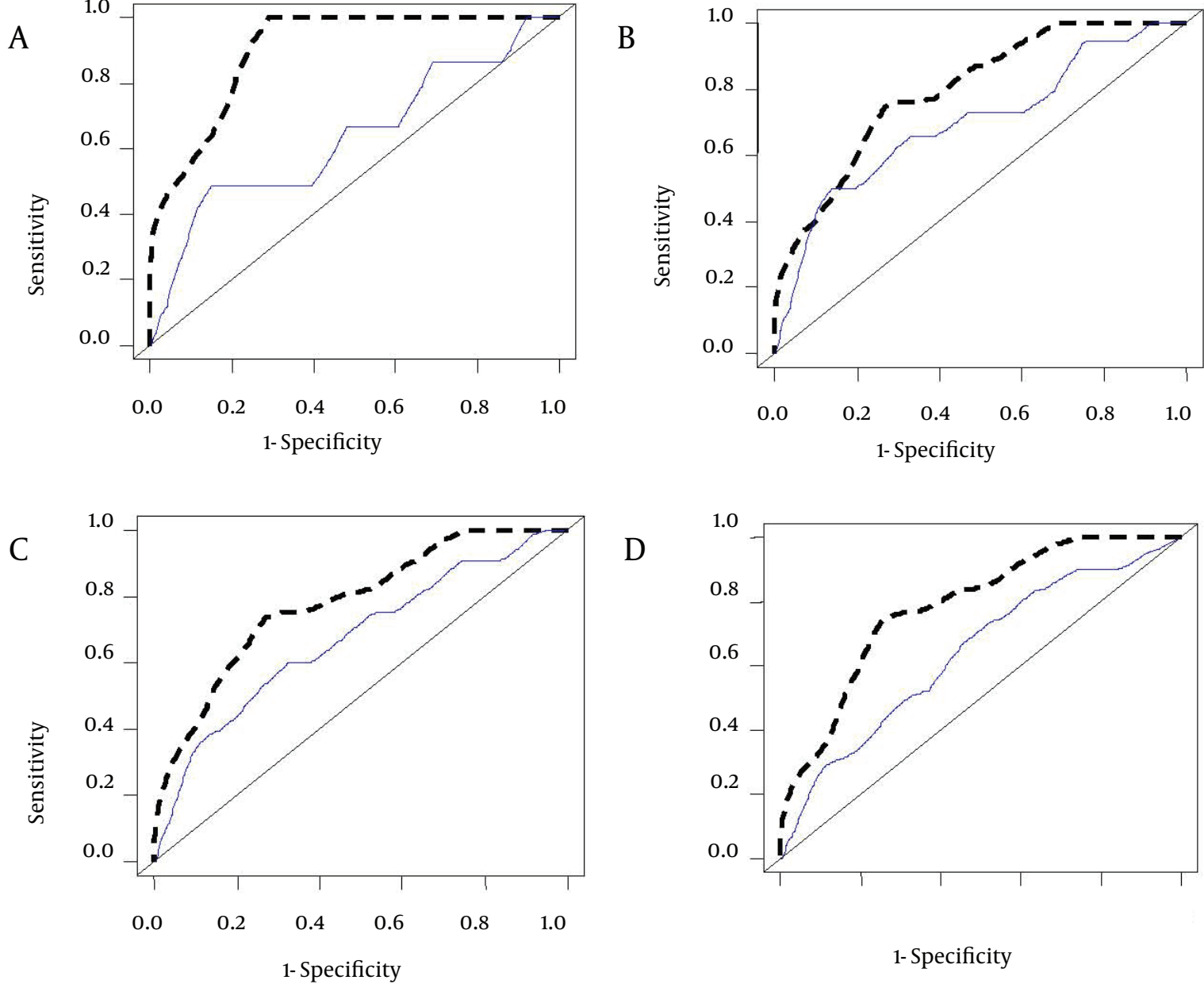

$\mathrm{D}$

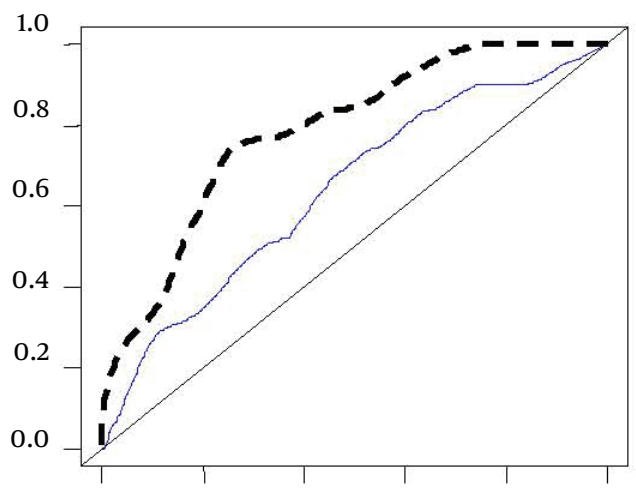

1- Specificity

Figure 4. Comparison of the Area Under the ROC Curves (AUC) for Predicting the Risk of Mortality at 3(A), 6(B), 9 (C)and 12 (D) Months Between NMELD (Dash Line) and MELD (Solid Line). AUC for Prediction of the Risk of Mortality at 3 (AUC $=0.916), 6$ (AUC $=0.811), 9($ AUC $=0.788)$ and 12 $($ AUC $=0.780)$ Months for the NMELD Score and AUC for Prediction of the Risk of Mortality at 3 (AUC =0.636), $6($ AUC $=0.697), 9($ AUC $=0.672)$ and 12 (AUC $=0.640)$ Months for MELD Score.

\section{Discussion}

LT has been accepted as an effective method for the recovery of health in patients with advanced liver disease. However, the increasing discrepancy between the number of patients on WLs and the number of available donor livers has a major impact on the mortality of these patients (38). Disease severity at the time of listing has been demonstrated as an important predictor of WL death.
Prognostic assessment of patients with liver cirrhosis is a vital subject that often challenges the clinicians. CP score is by far the most extensively used both in clinical practice and clinical research, and has stood the test of time for nearly 40 years. Recently, the MELD score has replaced the CP score in the United States for prioritizing liver donor allocation. Como et al. (39) showed that the use of the MELD score produced an advantage for Hepatocellular Carcinoma (HCC), but about one in every 11 viral hepatitis 
patients may be harmed using this scoring system.

Among the 305 patients in this study, who were listed for LT from May 2009 to May 2012, the most common etiology of liver disease was viral hepatitis (34.7\%). This is in contrast with the findings of the Malinchoc et al. study, conducted at a medical center in the USA where alcoholic liver cirrhosis was the most prevalent (38.8\% to 90.5\%) followed by viral hepatitis ( $4.8 \%$ to $10.4 \%$ ), and also with the results of a study by Sumskiene et al. in Lithuania where alcoholic liver cirrhosis was the most prevalent $(28.9 \%)$ followed by viral hepatitis $(17.8 \%)(40,41)$. This major difference is mainly due to the prohibition of alcohol by Islamic rules; therefore, alcoholic liver cirrhosis is not common in Iran. According to the data shown in Figure 4, NMELD score is superior to the MELD score in accurately predicting the risk of mortality in Iranian patients with advanced liver disease.

\section{Acknowledgements}

This paper is part of PhD dissertation at the School of Public Health affiliated to the Tehran University of Medical Sciences (TUMS) and was financially supported by this university. Hence, the authors would like to appreciate the support of Tehran University of Medical Sciences. We also would like to thank the Liver Transplantation Center of Imam Khomeini Hospital, especially Dr. Monavar Talebian and Mrs. Mojdeh Soltani for their kind assistance in collecting the data.

\section{Authors' Contribution}

All authors discussed the results and implications and commented on the manuscript at all stages.

\section{Financial Disclosure}

Authors who have no relevant financial interests are asked to provide a statement indicating that they have no financial interests related to the material in the manuscript.

\section{Funding/Support}

This paper is part of a PhD dissertation project conducted at the Health College of Tehran University of Medical Sciences (TUMS) and was financially supported by this university. Hence, the authors would like to appreciate the support of Tehran University of Medical Sciences.

\section{References}

1. Ganji A, Malekzadeh F, Safavi M, Nassri-Moghaddam S, Nourie M, Merat S, et al. Digestive and liver disease statistics in Iran. Middle East J Dig Dis. 2009;1(2):56-62.

2. Mansour-Ghanaei F, Mehrdad M, Mortazavi S, Joukar F, Khak M, Atrkar-Roushan Z. Decreased serum total T3 level in hepatitis B and $\mathrm{C}$ related cirrhosis by severity of liver damage. Ann Hepatol. 2012;11(5):667-71.
3. Boursier J, Cesbron E, Tropet AL, Pilette C. Comparison and improvement of MELD and Child-Pugh score accuracies for the prediction of 6-month mortality in cirrhotic patients. J Clin Gastroenterol. 2009;43(6):580-5

4. Child CG. [Remote Results of Portal Surgery in Liver Cirrhosis] Rev Int Hepatol. 1964;14:287-8.

5. Pugh RN, Murray-Lyon IM, Dawson JL, Pietroni MC, Williams R. Transection of the oesophagus for bleeding oesophageal varices. BrJ Surg. 1973;60(8):646-9.

6. Wehler M, Kokoska J, Reulbach U, Hahn EG, Strauss R. Short-term prognosis in critically ill patients with cirrhosis assessed by prognostic scoring systems. Hepatology. 2001;34(2):255-61.

7. Campbell DP, Parker DE, Anagnostopoulos CE. Survival prediction in portacaval shunts: a computerized statistical analysis. Am J Surg. 1973;126(6):748-51.

8. Child CG, Turcotte JG. Surgery and portal hypertension. Major Probl Clin Surg. 1964;1:1-85.

9. Freeman RB, Jr., Wiesner RH, Harper A, McDiarmid SV, Lake J, Edwards E, et al. The new liver allocation system: moving toward evidence-based transplantation policy. Liver Transpl. 2002;8(9):8518.

10. Wiesner RH, Edwards E, Freeman R, Harper A. Does the model for end-stage liver disease (MELD) predict post liver transplant graft survival? Hepat. 2003;38(4):370a-1a.

11. Onaca NN, Levy MF, Sanchez EQ, Chinnakotla S, Fasola CG, Thomas MJ, et al. A correlation between the pretransplantation MELD score and mortality in the first two years after liver transplantation. Liver Transpl. 2003;9(2):117-23.

12. Saab S, Wang V, Ibrahim AB, Durazo F, Han S, Farmer DG, et al. MELD score predicts 1-year patient survival post-orthotopic liver transplantation. Liver Transpl. 2003;9(5):473-6.

13. Kamath PS, Wiesner RH, Malinchoc M, Kremers W, Therneau TM Kosberg CL, et al. A model to predict survival in patients with end-stage liver disease. Hepatology. 2001;33(2):464-70.

14. Mendez-Sanchez N, Almeda-Valdes P, Uribe M. Alcoholic liver disease. An update. Ann Hepatol. 2005;4(1):32-42.

15. Huo TI, Lee SD, Lin HC. Selecting an optimal prognostic system for liver cirrhosis: the model for end-stage liver disease and beyond. Liver Int. 2008;28(5):606-13.

16. Tsoulfas G, Agorastou P. Role of living donor liver transplantation in the treatment of hepatitis $\mathrm{C}$ virus infection. Hepat Mon 2011;11(6):427-33.

17. Samada Suarez M, Hernandez Perera JC, Ramos Robaina L, Barroso Marquez L, Gonzalez Rapado L, Cepero Valdes M, et al. Factors that predict survival in patients with cirrhosis considered for liver transplantation. Transplant Proc. 2008;40(9):2965-7.

18. Kim YS, Um SH, Ryu HS, Lee JB, Lee JW, Park DK, et al. The prognosis of liver cirrhosis in recent years in Korea. J Korean Med Sci. 2003;18(6):833-41.

19. Olthoff KM, Brown RS, Jr., Delmonico FL, Freeman RB, McDiarmid $\mathrm{SV}$, Merion RM, et al. Summary report of a national conference: Evolving concepts in liver allocation in the MELD and PELD era December 8, 2003, Washington, DC, USA. Liver Transpl. 2004;10(10 Suppl 2):A6-22.

20. Merion RM. When is a patient too well and when is a patient too sick for a liver transplant? Liver Transpl. 2004;10(10 Suppl 2):S6973.

21. Durand F, Valla D. Assessment of the prognosis of cirrhosis: Child-Pugh versus MELD. J Hepatol. 2005;42 Suppl(1):S100-7.

22. Oberkofler CE, Dutkowski P, Stocker R, Schuepbach RA, Stover JF, Clavien PA, et al. Model of end stage liver disease (MELD) score greater than 23 predicts length of stay in the ICU but not mortality in liver transplant recipients. Crit Care. 2010;14(3):R117.

23. Orloff MJ, Vaida F, Isenberg JI, Wheeler HO, Haynes KS, JinichBrook H, et al. Child-Turcotte score versus MELD for prognosis in a randomized controlled trial of emergency treatment of bleeding esophageal varices in cirrhosis. J Surg Res. 2012;178(1):139-46.

24. Craig DG, Reid TW, Wright EC, Martin KG, Davidson JS, Hayes PC, et al. The sequential organ failure assessment (SOFA) score is prognostically superior to the model for end-stage liver disease 
(MELD) and MELD variants following paracetamol (acetaminophen) overdose. Aliment Pharmacol Ther. 2012;35(6):705-13.

25. Mukerji AN, Patel V, Jain A. Improving survival in decompensated cirrhosis. Int J Hepatol. 2012;2012:318627.

26. Ghadir MR, Riahin AA, Havaspour A, Nooranipour M, Habibinejad AA. The relationship between lipid profile and severity of liver damage in cirrhotic patients. Hepat Mon. 2010;10(4):285-8.

27. Ahn J, Cohen SM. Prevention of hepatitis B recurrence in liver transplant patients using oral antiviral therapy without longterm hepatitis B immunoglobulin. Hepat Mon. 2011;11(8):638-45

28. Freeman RB, Wiesner RH, Edwards E, Harper A, Merion R, Wolfe R. Results of the first year of the new liver allocation plan. Liver Transpl. 2004;10(1):7-15.

29. Saberifiroozi M, Serati AR, Malekhosseini SA, Salahi H, Bahador A, Lankarani KB, et al. Analysis of patients listed for liver transplantation in Shiraz, Iran. Indian J Gastroenterol. 2006;25(1):11-3.

30. Ghods AJ, Mahdavi M. Organ transplantation in Iran. Saudi J Kidney Dis Transpl. 2007;18(4):648-55.

31. Mahmoudi H, Jafari P, Alizadeh-Naini M, Gholami S, Malek-Hosseini SA, Ghaffaripour S. Validity and reliability of Persian version of Chronic Liver Disease Questionnaire (CLDQ). Qual Life Res. 2012;21(8):1479-85.

32. Lankarani KB, Mahmoodi M, Gholami S, Mehravar S, Malekhosseini SA, Heydari ST, et al. Reducing Social Disparity in Liver Transplantation Utilization through Governmental Financial Support. Hepat Mon. 2012;12(11).

33. Klein JP, Moeschberger ML. Survival analysis: techniques for cen- sored and truncated data. Springer; 2003.

34. Heuman DM, Mihas AA, Habib A, Gilles HS, Stravitz RT, Sanyal AJ, et al. MELD-XI: a rational approach to "sickest first" liver transplantation in cirrhotic patients requiring anticoagulant therapy. Liver Transpl. 2007;13(1):30-7.

35. Heagerty PJ, Lumley T, Pepe MS. Time-dependent ROC curves for censored survival data and a diagnostic marker. Biometrics. 2000;56(2):337-44.

36. Hanley JA, McNeil BJ. The meaning and use of the area under a receiver operating characteristic (ROC) curve. Radiology. 1982;143(1):29-36.

37. Heagerty PJ, Zheng Y. Survival model predictive accuracy and ROC curves. Biometrics. 2005;61(1):92-105.

38. Cai CJ, Chen HA, Lu MQ, Chen GH. Model for end-stage liver disease-sodium predicts prognosis in patients with chronic severe hepatitis B. Chin Med J (Engl). 2008;121(20):2065-9.

39. Cuomo O, Perrella A, Arenga G. Model for End-Stage Liver Disease (MELD) score system to evaluate patients with viral hepatitis on the waiting list: better than the Child-Turcotte-Pugh (CTP) system? Transplant Proc. 2008;40(6):1906-9.

40. Sumskiene J, Kupcinskas L, Pundzius J, Sumskas L. Prognostic factors for short and long-term survival in patients selected for liver transplantation. Medicina (Kaunas). 2005;41(1):39-46.

41. Malinchoc M, Kamath PS, Gordon FD, Peine CJ, Rank J, ter Borg PC. A model to predict poor survival in patients undergoing transjugular intrahepatic portosystemic shunts. Hepatology. 2000;31(4):864-71. 